\title{
Out-of-Hospital Administration of Medication without Prescription and Associated Factors among Preschool Children
}

\author{
Fotini Andritsou, ${ }^{1}$ Vassiliki Benetou, ${ }^{2}$ Koralia A. Michail, ${ }^{1}$ \\ Nikolaos Pantazis, ${ }^{2}$ and Ioanna D. Pavlopoulou ${ }^{1}$ \\ ${ }^{1}$ Pediatric Research Laboratory, Faculty of Nursing, National and Kapodistrian University of Athens, Athens, Greece \\ ${ }^{2}$ Department of Hygiene, Epidemiology and Medical Statistics, Faculty of Medicine, \\ National and Kapodistrian University of Athens, Athens, Greece
}

Correspondence should be addressed to Koralia A. Michail; koraliamnurs@hotmail.com

Received 5 March 2017; Revised 2 June 2017; Accepted 5 September 2017; Published 10 October 2017

Academic Editor: Paul M. Tulkens

Copyright (C) 2017 Fotini Andritsou et al. This is an open access article distributed under the Creative Commons Attribution License, which permits unrestricted use, distribution, and reproduction in any medium, provided the original work is properly cited.

\begin{abstract}
The increasing trend of administering nonprescribed medicines in children is a significant public health issue. The aim of the present study was to assess the use of medication without a prescription (MWP), including both nonprescribed medication (NPM) and prescription-only medication (POM), and identify associated factors, among preschoolers in Athens, Greece. A predesigned questionnaire was distributed to parents from May through June 2011. Multivariable binary logistic regression analysis models were used to assess associations of interest. Results showed that $95.1 \%$ of parents reported administering at least one MWP, during the previous 12 months. Antipyretics (91\%) were the most commonly NPM and bronchodilators (24.8\%) and antibiotics (16.4\%) the most common POM dispensed. Child's increased age group, lack of parental information, higher paternal education, and mother's foreign nationality were associated with increased antipyretic use $(p<0.05)$, while father's foreign nationality and parental age were positive predictors of antibiotic administration $(p<0.05)$. The likelihood of consuming antipyretics and antibiotics significantly increased when information was provided by a pharmacist ( $p=0.017$ and $p=0.054$, resp.). Conclusively, most parents have administered at least one MWP, including antibiotics, to address symptoms of common childhood diseases, highlighting the need of information campaigns concerning the consequences of their improper use.
\end{abstract}

\section{Introduction}

A trend towards increased use of over-the-counter medicines, namely, those drugs that can be administered without a prescription (nonprescribed medication, NPM), has been observed in several developed countries, even among younger children $[1,2]$. These include analgesics-antipyretics, cough and cold medicines, decongestants, and antihistamines, as well as various dermatological preparations, laxatives, and antiseptics [3, 4].

Studies have shown that increased consumption of NPM is associated with an increased rate of side effects, especially when administered without guidance from a health professional $[1,2,5]$. Recent estimates describe that $8 \%$ of pediatric emergency department visits are related to medication use, and $65 \%$ of them are deemed preventable [5]. According to information provided by the Poison Control Centre of the United States, over 200,000 cases of medication-related errors have been recorded since 2003 in the community, with $30 \%$ involving children [6]. Additional reports state that $23-73 \%$ of preschool children have taken NPM in the past $[1,2,7]$. Although there is plenty of information on the consumption of NPM among children in several countries, evidence regarding the reasons or indications which prompt parents to their use, as well as other associated factors, is limited [7-9].

In Greece, data on consumption of NPM in children lacks despite the fact that these were, until recently, provided only by a pharmacist with or without a doctor's prescription. Moreover, illicit dispensing of prescription-only medicines 
(POM), including antibiotics, at local pharmacies without a medical prescription, remains a standard practice $[10,11]$.

The aim of the present study was to evaluate the frequency of administration of medicines without the use of a prescription (MWP) for both NPM and drugs that require a prescription but are paradoxically dispensed without it (POM), in a sample of preschool children in the Municipality of Athens. A secondary objective was to investigate the factors associated with the administration of two representative categories-analgesics-antipyretics and antibiotics-in the above population.

\section{Materials and Methods}

2.1. Population. A cross-sectional study was conducted the public kindergartens of the Municipality of Athens from May through June 2011. The above area consists of 98 nursery schools with a total of 5,401 registered pupils of middle and low-income families. Parents of children less than six years of age were eligible for participation.

2.2. Instrumentation. A modified questionnaire, comprising 11 sections, based on previously published surveys with the approved consent of the authors, was used for data collection $[1,2,7-9]$. Its format was finalized after a pilot test in a small number of parents that were excluded from the final study. All school teachers were informed through interactive sessions organized by the investigators. Parents/guardians were informed through both faculty and an explanatory letter and were asked to complete the questionnaires that were collected three weeks later. Consent was implied by returning of a completed questionnaire. The study protocol was approved by the review board of the Municipal Nursery of Athens.

2.3. Statistical Analysis. Data analysis was performed with the use of the Statistical Package for Social Sciences (SPSS) Ver.17. The mean values and standard deviations or the median values and interquartile range (IQR) were calculated for continuous variables, and frequencies and percentages were calculated for categorical and arranged variables.

Multiple variable analysis was used to draw quantitative conclusions for the 13 categories of MWP (NPMs and POM) in relation to the symptoms for which they were administered by the corresponding number of parents. Symptoms reported by the parents were grouped to the most frequent and were coded with the use of multiple response sets. Questionnaires in which parents did not state the symptoms, for which they administered a particular MWP, were excluded. Multivariable Binary Logistic regression was used to investigate the association of each of the 13 MWP categories with demographics, the way medicines are prescribed, the sources sought for information regarding their administration, and the reasons that motivated or discouraged parents to buy and use them, at the significance level $5 \%$ or $10 \%$ in some cases. The results were presented in Odds Ratios (OR) together with the corresponding $p$ values and 95\% (CI) Confidence Intervals. The variables that were selected to be used in the final model of multiple logistic regression analysis were based on the international literature and at statistically significant results of the univariate analysis (univariable binary logistic regression) and $\chi^{2}$ test. The most frequent category in each variable/factor was selected as reference category $(\mathrm{OR}=1)$ in the categorical variables multifactorial models, whereas the assessment of each associated factor was weighted for all other factors in the model.

\section{Results}

A total of 4,608 questionnaires were distributed to 87 kindergartens of the Municipality of Athens, and 1,985 were returned (participation rate: $43.1 \%$ ). The mean age of parents was $36.6 \pm 5.2$ years while the majority of respondents were mothers $(79 \%)$. A percentage of $88 \%$ of parents had positive marital status with $74.3 \%$ of both parents being Greeks. Most of them were high school graduates $(46.3 \%$ and $44.7 \%$ for paternal and maternal education, resp.) while in $29 \%$ at least one had higher education. Among children that had received MWP within the 12-month period before the study, $57.2 \%$ were firstborns, whereas $65.5 \%$ had siblings. Among participating parents, 95.1\% stated administering at least one of the 13 categories of medicines included in the questionnaire, without a medical prescription. Of these 13 categories, antipyretics-analgesics (91\%) were administered more frequently, followed by dermatological preparations (37.3\%) and cough and cold medicines (34.4\%). Among POM, bronchodilators $(24.8 \%)$ were the preferred category, followed by antibiotics (16.4\%).

The majority of parents admitted that fever was the main reason for using antipyretics- analgesics NPM (78\%). Acetaminophen was the preferred antipyretic (57.2\%), followed by mefenamic acid (35.1\%) (Table 1). The most common use of antibiotics was due to upper respiratory infection $(45.5 \%)$, with amoxicillin being the formulation of choice (41.4\%, Table 2).

3.1. Factors Associated with the Administration of AntipyreticsAnalgesics. According to the results of multiple logistic regression (Table 3), children belonging to the age group of 4-6 years were more likely to receive antipyretics-analgesic drugs compared to those aged 2-4 and those older than 6 years $[(\mathrm{OR}=0.61, p=0.013)$ and $(\mathrm{OR}=0.07, p=0.004)$, resp.]. Fathers with postgraduate education were $64 \%$ less likely $(\mathrm{OR}=0.36, p=0.002)$ to administer antipyreticsanalgesics, compared to secondary school graduates, whereas mothers with Greek nationality were $25 \%$ less likely to use the above medication category when compared to mothers of foreign nationality $(\mathrm{OR}=1.75, p=0.038)$.

Parents not familiar with the term "medicines without prescription" appeared to have lower possibilities $(\mathrm{OR}=0.26$, $p \leq 0.001)$ of administering antipyretic-analgesics, compared to those who knew the meaning of the term. Notably, those who did not respond to the above query were nearly three times more likely $(\mathrm{OR}=3.27, p<0.001)$ to administer the medicines mentioned above.

The rapid and timely communication between parents and the pediatrician, in less than one day, seemed to reduce the likelihood of administering antipyretic-analgesics by $62 \%$ 
TABLE 1: Nonprescribed medicines: administration of antipyretics-analgesics (AA) according to child's symptoms.

\begin{tabular}{|c|c|c|c|c|c|c|c|c|}
\hline Active substance & $\begin{array}{c}\text { Fever } \\
N,(\%)^{*}\end{array}$ & $\begin{array}{c}\text { Fever \& pain } \\
N,(\%)^{*}\end{array}$ & $\begin{array}{c}\text { Cold } \\
N,(\%)^{*}\end{array}$ & $\begin{array}{l}\text { High fever } \\
N,(\%)^{*}\end{array}$ & $\begin{array}{c}\text { Localized pain } \\
N,(\%)^{*} \\
\end{array}$ & $\begin{array}{c}\text { Pain } \\
N,(\%)^{*}\end{array}$ & $\begin{array}{c}\text { Cough } \\
N,(\%)^{*}\end{array}$ & $\begin{array}{c}\text { Total } \\
N,(\%)^{* *}\end{array}$ \\
\hline Acetaminophen & $1255(57.1)$ & $160(66.1)$ & $88(63.8)$ & $42(40.8)$ & $27(61.4)$ & $7(77.8)$ & $2(66.7)$ & $1581(57.8)$ \\
\hline Mefenamic acid & $773(35.2)$ & $60(24.8)$ & $42(30.4)$ & $45(43.7)$ & $12(27.3)$ & $1(11.1)$ & $1(33.3)$ & $934(34.1)$ \\
\hline Tolfenamic acid & $96(4.4)$ & $11(4.6)$ & $4(3.0)$ & $7(6.8)$ & $0(0.0)$ & $0(0.0)$ & $0(0.0)$ & $118(4.3)$ \\
\hline Ibuprofen & $70(3.2)$ & $10(4.1)$ & $3(2.2)$ & $9(8.7)$ & $4(9.1)$ & $1(11.1)$ & $0(0.0)$ & $97(3.6)$ \\
\hline Acetylsalicylic acid & $3(0.2)$ & $1(0.4)$ & $1(0.7)$ & $0(0.0)$ & $1(2.3)$ & $0(0.0)$ & $0(0.0)$ & $6(0.2)$ \\
\hline $\begin{array}{l}\text { Total N1 (\%) of } \\
\text { medicines }\end{array}$ & $2197(100.0)$ & $242(100.0)$ & $138(100.0)$ & $103(100.0)$ & $44(100.0)$ & $9(100.0)$ & $3(100.0)$ & $2736(100.0)$ \\
\hline Total N2 (\%) of parents & $1379(78.0)^{* * *}$ & $180(10.2)$ & $92(5.2)$ & $68(3.9)$ & $39(2.2)$ & $8(0.5)$ & $2(0.1)$ & $1768(100.0)$ \\
\hline
\end{tabular}

N1: number (\%) of AA medicines administered in total for each symptom. N2: number (\%) of parents administering AA for each symptom. ${ }^{*}$ Number (\%) of each AA formulation administered for each symptom over the total number of AA given for the same symptom. ${ }^{* *}$ Number (\%) of each AA formulation administered for all symptoms over the total number of medicines. ${ }^{* * *}$ The number $(\%)$ of parents administering AA for fever over the total number of parents using AA for all symptoms.

$(\mathrm{OR}=0.38, p<0.001)$ compared to the delayed one. Reduced risk of delivering antipyretics-analgesics was observed among parents that were uncertain and lacked appropriate information regarding the administered NPM $(\mathrm{OR}=0.49, p=0.009)$, as well as among those who did not provide any answer to the query on being aware of the active ingredients of the NPM they wished to administer ( $\mathrm{OR}=0.25, p=0.003)$.

Parents who did not receive information from various sources, such as the pharmacist, the Internet, relatives, or magazines, appeared to have a reduced likelihood of administering antipyretic-analgesics by $53 \%(\mathrm{OR}=0.47, p=$ 0.030 ). However, increased likelihood of administration of the medicines above was observed when information was obtained by the pharmacist ( $\mathrm{OR}=1.77, p=0.017)$ and by relatives $(\mathrm{OR}=7.47, p=0.030)$. In contrast, those informed by television and the Internet had a reduced likelihood of administration by $96 \%(\mathrm{OR}=0.04, p<0.001)$ and $62 \%(\mathrm{OR}$ $=0.38, p=0.016)$, respectively.

\subsection{Factors Associated with the Administration of Antibiotics.} Administration of antibiotics without prescription was 53\% more likely when the father was the responding person (OR $=1.53 \%, p=0.012$ ), increased by 2.2 times if the father was of foreign nationality and by 2.6 times $(\mathrm{OR}=2.62, p=0.009)$ if the question regarding citizenship was not completed.

Those who did not agree with the practice of buying medicines with the use of a previous prescription in order to manage a similar health problem of their child, as well as those who did not agree that a familiar brand name of a drug should drive to its purchase without a prescription, were less likely to administer antibiotics by $39 \%$ and $40 \%$, respectively $[(\mathrm{OR}=0.61, p=0.001)$ and $(\mathrm{OR}=0.60, p=$ $0.001)$ ]. Finally, those disagreeing with the view that the administration of medicines should be preceded by a visit to the pediatrician were 2.8 times more probable to administer antibiotics without prescription (OR $=2.81, p<0.001)$.

Similarly to the analgesic-antipyretic category, the provision of relevant information by the pharmacist appeared to increase the likelihood of antibiotic administration without a prescription by $31 \%(\mathrm{OR}=1.31, p=0.054)$ (Table 4$)$.

\section{Discussion}

This is the first study to provide information concerning the out-of-hospital consumption of MWP, including NPM and $\mathrm{POM}$, as well as the factors influencing the administration of certain categories, among a large sample of preschool children of the Municipality of Athens, Greece. According to our findings, the vast majority of parents have administered at least one MWP, including antibiotics, to address the symptoms of common childhood diseases. Factors associated with the use of MWP, particularly analgesic-antipyretics and antibiotics, were the child's age, father's education, and parental nationality, as well as knowledge and information regarding NPM, their source of advice, with most representative the pharmacist, and finally their general knowledge and perceptions concerning the purchase and use of the MWP.

As reported by recent data, NPM in children is often used without sufficient indication, thus increasing the risk of adverse reactions $[8,12]$. Therefore, international scientific organizations as well as state health agencies, including the World Health Organization and the US Food and Drug Administration (FDA), have mainly emphasized informing parents about the dangers following the administration of those NPM that are most widely consumed and often considered harmless [12-15]. The upward trend in NPM consumption in children, especially those used for the treatment of fever and the common cold, has been well described worldwide $[1,2,16,17]$. Results from a previous study showed that $98.1 \%$ of parents in different countries had used at least one NPM for their children in the 12-month period before the collection of relevant data, a proportion similar to that recorded in the present study $[1,2]$. The latter was an interesting finding because until now the supply of NPM in our country was possible only through pharmacies, leading to the assumption that this would possibly result in their reduced consumption.

According to our results, fever was the main symptom for the administration of antipyretics, while acetaminophen was the preferred formulation, followed by mefenamic acid. Children belonging to the age group of 4-6 years were more 


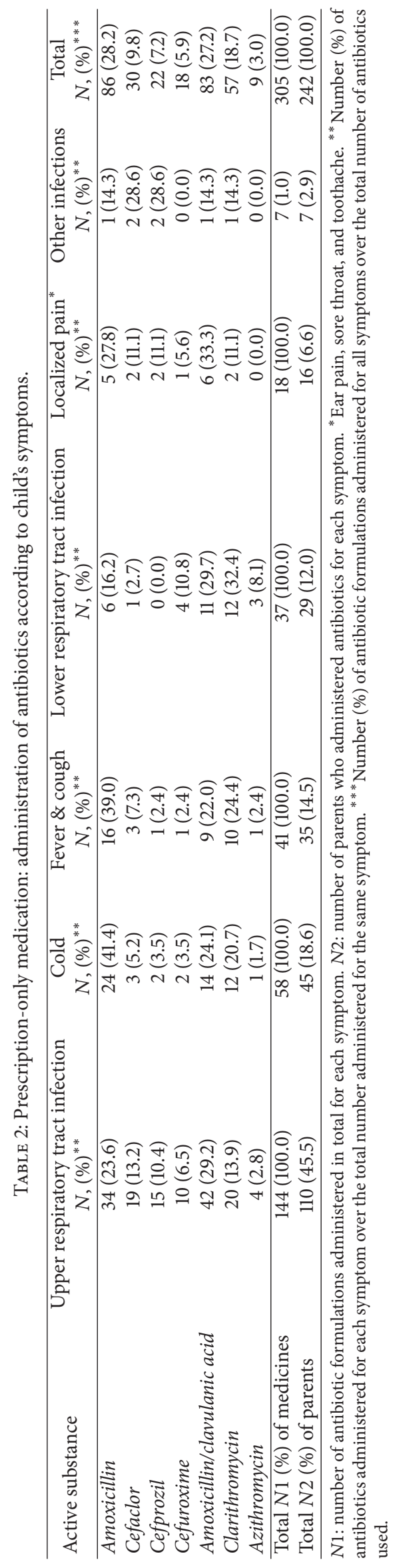


TABLE 3: Multivariable model to explore factors associated with the administration of antipyretics-analgesics.

\begin{tabular}{|c|c|c|c|}
\hline Factors & $\mathrm{OR}^{* *}$ & $(95 \% \text { C.I })^{* * *}$ & $p$ value \\
\hline Child's age group in years & & & 0.011 \\
\hline$\leq 2$ & 0.64 & $(0.242-1.684)$ & 0.364 \\
\hline$>2-4$ & 0.61 & $(0.416-0.902)$ & 0.013 \\
\hline$>4-6^{*}$ & 1 & & \\
\hline$\geq 6$ & 0.07 & $(0.012-0.427)$ & 0.004 \\
\hline No answer & 1.21 & $(0.245-6.021)$ & 0.813 \\
\hline Father's educational level & & & 0.018 \\
\hline Compulsory & 0.6 & $(0.351-1.016)$ & 0.057 \\
\hline High school graduate ${ }^{*}$ & 1 & & \\
\hline University graduate & 0.69 & $(0.440-1.071)$ & 0.097 \\
\hline Postgraduate & 0.36 & $(0.192-0.684)$ & 0.002 \\
\hline No answer & 1.07 & $(0.348-3.306)$ & 0.903 \\
\hline Mother's nationality & & & 0.038 \\
\hline Greek $^{*}$ & 1 & & \\
\hline Others & 1.75 & $(1.030-2.983)$ & 0.038 \\
\hline Marital status & & & 0.04 \\
\hline Married $^{*}$ & 1 & & \\
\hline Single & 0.79 & $(0.365-1.729)$ & 0.561 \\
\hline Divorced & 0.36 & $(0.160-0.795)$ & 0.012 \\
\hline Are you familiar with the term "medicines given without prescription" & & & $<0.001$ \\
\hline No & 0.27 & $(0.139-0.503)$ & $<0.001$ \\
\hline Yes* $^{*}$ & 1 & & \\
\hline No answer & 3.27 & $(1.808-5.905)$ & $<0.001$ \\
\hline Time elapsed before requesting paediatric consultation & & & $<0.001$ \\
\hline$<1$ day & 0.38 & $(0.237-0.610)$ & $<0.001$ \\
\hline $1-2$ days $^{*}$ & 1 & & \\
\hline $2-4$ days & 1.8 & $(0.818-3.981)$ & 0.144 \\
\hline$>4$ days & 0.91 & $(0.303-2.744)$ & 0.87 \\
\hline I did not ask for consultation & 0.4 & $(0.188-0.831)$ & 0.014 \\
\hline No answer & 0.24 & $(0.114-0.512)$ & $<0.001$ \\
\hline Did you first refer to the pharmacy box in your house? & & & 0.048 \\
\hline No & 0.83 & $(0.530-1.315)$ & 0.435 \\
\hline Yes $^{*}$ & 1 & & \\
\hline No answer & 0.35 & $(0.154-0.809)$ & 0.014 \\
\hline Were you certain that you had all relevant information? & & & 0.032 \\
\hline No & 0.49 & $(0.287-0.836)$ & 0.009 \\
\hline Yes $^{*}$ & 1 & & \\
\hline No answer & 1.02 & $(0.382-2.730)$ & 0.967 \\
\hline $\begin{array}{l}\text { Were you aware of the active substances and ingredients included in the } \\
\text { medicines you administered? }\end{array}$ & & & 0.011 \\
\hline No & 0.97 & $(0.611-1.545)$ & 0.903 \\
\hline Yes $^{*}$ & 1 & & \\
\hline No answer & 0.25 & $(0.102-0.624)$ & 0.003 \\
\hline I tend to buy medicines that are advertised & & & $<0.001$ \\
\hline $\mathrm{No}^{*}$ & 1 & & \\
\hline Yes & 0.35 & $(0.134-0.907)$ & 0.031 \\
\hline No answer & 103.09 & $(11.920-891.554)$ & $<0.001$ \\
\hline
\end{tabular}


TABLE 3: Continued.

\begin{tabular}{|c|c|c|c|}
\hline Factors & $\mathrm{OR}^{* *}$ & $(95 \% \text { C.I })^{* * *}$ & $p$ value \\
\hline I tend to buy medicines that friends or relatives have used & & & 0.004 \\
\hline $\mathrm{No}^{*}$ & 1 & & \\
\hline Yes & 0.59 & $(0.208-1.690)$ & 0.328 \\
\hline No answer & 0.04 & $(0.005-0.274)$ & 0.001 \\
\hline Were you informed by several sources regarding the medication? & & & 0.03 \\
\hline No & 0.47 & $(0.236-0.930)$ & 0.03 \\
\hline Yes $^{*}$ & 1 & & \\
\hline Were you informed by the pharmacist? & & & 0.017 \\
\hline $\mathrm{No}^{*}$ & 1 & & \\
\hline Yes & 1.77 & $(1.106-2.815)$ & 0.017 \\
\hline Were you informed by relatives? & & & 0.03 \\
\hline $\mathrm{No}^{*}$ & 1 & & \\
\hline Yes & 7.47 & $(1.216-45.926)$ & 0.03 \\
\hline Were you informed by a $T V$-advertisement? & & & $<0.001$ \\
\hline $\mathrm{No}^{*}$ & 1 & & \\
\hline Yes & 0.04 & $(0.007-0.188)$ & $<0.001$ \\
\hline Were you informed by the Internet? & & & 0.016 \\
\hline $\mathrm{No}^{*}$ & 1 & & \\
\hline Yes & 0.38 & $(0.169-0.836)$ & 0.016 \\
\hline
\end{tabular}

${ }^{*}$ Reference category; ${ }^{* *} \mathrm{OR}=$ Odds Ratio; ${ }^{* * *} 95 \% \mathrm{CI}=95 \%$ Confidence Interval.

likely to receive antipyretics-analgesics compared to those of 2-4 years old, possibly due to the increasing confidence of parents with their child's advancing age. Similar studies performed by others report that more than $50 \%$ of preschool children have used NPM, most frequently those less than two years of age, with acetaminophen being the medicine of choice for the treatment of fever and pain $[1,2,16-18]$. This difference may be attributed to the fact that children in our country enroll in kindergartens and are consequently exposed to infections, at older ages. The use of mefenamic acid instead of ibuprofen as a second-choice antipyretic may be attributed to the familiarity of this formulation in Greece.

Since May 2011, the Food and Drug Administration Committee, responsible for NPM, issued new guidelines for the administration of acetaminophen removing the indication "pain relief" from the packaging as well as from the package inserts, for both infants and young children, considering that there is no reliable evidence of its effectiveness in relieving pain compared to placebo, especially for children under the age of two years [19]. It is noteworthy that acetaminophen has been described as the most common cause of acute liver failure in the US, which may occur at younger ages even when the dose is within the recommended limits [20]. The above measures are expected to decrease the incidence of adverse events attributed to acetaminophen as well as its overuse, following the example of a cough and cold medication restriction by the FDA in 2008 [21, 22].

This study showed that, among antibiotics delivered to children without a prescription, second generation cephalosporins were most frequently administered for the treatment of upper respiratory tract infections, whereas amoxicillin was administered for common cold symptoms. It is well known that infections of the upper respiratory tract are the most common cause of antibiotic use in everyday pediatric practice even though their majority are of viral origin and do not require antimicrobial treatment [23]. According to reports by the European Agency of Surveillance of Antibiotic Consumption (ESAC), Greece is the European country with the most extensive use of antibiotics in the community, which appears to have further increased by $25 \%$ during the economic crisis $[11,23,24]$. More specifically, cefuroxime use has been recorded to have an upward trend as a treatment option for infections of the respiratory tract [11, 24]. Interestingly, in a survey conducted in Greece in 2014, among 60\% of respondents that received information concerning antibiotic consumption by media, only 1 in 5 was aware that these were prescription-only medicines. Unfortunately, this malpractice is ongoing despite the fact that antimicrobials are classified by law, since 1976, as "strictly prescription-only medicines" [11] and despite the implementation of a nationwide electronic drug prescription system during the last few years. Part of the problem is the ease with which pharmacists provide these medicines, as has been recorded in previous studies conducted in our country $[25,26]$. In our study, the incidence of children using antibiotics without prescription was lower, compared to another similar study concerning adults where the respective use of was $18.6 \%$ [11]. Even though we found that antibiotics were administered at a significantly lower rate than other medicines, their average use was more extensive than that of dermatological or cough preparations. Specifically, the majority of parents marked all seven different groups of trade names of antibiotics that were provided in the 
TABLE 4: Multivariable model for the exploration of factors associated with the administration of antibiotics.

\begin{tabular}{|c|c|c|c|}
\hline Factor & O. $\mathrm{R}^{* *}$ & $(95 \% \text { C.I. })^{* * *}$ & $p$ value \\
\hline Parental age & 0.97 & $(0.946-1.002)$ & 0.067 \\
\hline Gender of parent completing the questionnaire & & & 0.032 \\
\hline Male & 1.53 & $(1.098-2.137)$ & 0.012 \\
\hline Female $^{*}$ & 1 & & \\
\hline No answer & 3.61 & $(0.239-54.550)$ & 0.354 \\
\hline Father's nationality & & & $<0.001$ \\
\hline Greek $^{*}$ & 1 & & \\
\hline Other & 2.22 & $(1.619-3.041)$ & $<0.001$ \\
\hline No answer & 2.62 & $(1.270-5.414)$ & 0.009 \\
\hline Time elapsed before requesting pediatric consultation & & & 0.054 \\
\hline$<1$ day & 1.04 & $(0.751-1.451)$ & 0.799 \\
\hline $1-2$ days $^{*}$ & 1 & & \\
\hline $2-4$ days & 1.05 & $(0.715-1.527)$ & 0.822 \\
\hline$>4$ days & 1.65 & $(0.908-3.006)$ & 0.1 \\
\hline I did not ask for consultation & 0.43 & $(0.213-0.882)$ & 0.021 \\
\hline No answer & 0.59 & $(0.262-1.318)$ & 0.197 \\
\hline $\begin{array}{l}\text { Did you try to remember how you acted in the past in a similar } \\
\text { situation regarding another of your children? }\end{array}$ & & & 0.095 \\
\hline No & 0.97 & $(0.722-1.304)$ & 0.84 \\
\hline Yes* $^{*}$ & 1 & & \\
\hline No answer & 0.58 & $(0.349-0.956)$ & 0.033 \\
\hline The residual medicine you: & & & $<0.001$ \\
\hline Threw away & 2.49 & $(1.851-3.344)$ & $<0.001$ \\
\hline Kept for future use ${ }^{*}$ & 1 & & \\
\hline No answer & 1.35 & $(0.693-2.628)$ & 0.378 \\
\hline $\begin{array}{l}\text { I buy medicines prescribed by my pediatrician in the past that I know } \\
\text { are suitable for this particular health issue }\end{array}$ & & & 0.005 \\
\hline I disagree & 0.61 & $(0.454-0.827)$ & 0.001 \\
\hline I agree* & 1 & & \\
\hline No answer & 1.01 & $(0.421-2.424)$ & 0.982 \\
\hline I buy medicines that are popular by name & & & 0.001 \\
\hline I disagree & 0.6 & $(0.451-0.807)$ & 0.001 \\
\hline I agree* & 1 & & \\
\hline No answer & 1.37 & $(0.664-2.845)$ & 0.392 \\
\hline I consult my pediatrician before administering any medication & & & $<0.001$ \\
\hline I disagree & 2.81 & $(1.981-3.981)$ & $<0.001$ \\
\hline I agree $^{*}$ & 1 & & \\
\hline No answer & 2.62 & $(1.053-6.519)$ & 0.038 \\
\hline $\begin{array}{l}\text { I am able to tell whether my child's health issue is not serious and can } \\
\text { therefore wait without using any treatment }\end{array}$ & & & 0.022 \\
\hline I disagree ${ }^{*}$ & 1 & & \\
\hline I agree & 0.77 & $(0.583-1.027)$ & 0.076 \\
\hline No answer & 2.61 & $(0.977-6.993)$ & 0.056 \\
\hline $\begin{array}{l}\text { The difficulty of finding an open pharmacy discourages me from using } \\
\text { medicines }\end{array}$ & & & 0.002 \\
\hline I disagree $^{*}$ & 1 & & \\
\hline I agree & 1.45 & $(1.077-1.939)$ & 0.014 \\
\hline No answer & 0.33 & $(0.125-0.854)$ & 0.022 \\
\hline Were you informed by the pharmacist? & & & 0.054 \\
\hline $\mathrm{No}^{*}$ & 1 & & \\
\hline Yes & 1.31 & $(0.996-1.724)$ & 0.054 \\
\hline
\end{tabular}

${ }^{*}$ Reference category; ${ }^{* *}$ OR = Odds Ratio; ${ }^{* * *} 95 \% \mathrm{CI}=95 \%$ Confidence Interval. 
questionnaire, namely, more than the particular formulations of the other drug categories, indicating their widespread use in the community.

The lower educational level and foreign nationality appeared to increase the possibility of administration of antipyretics and antibiotics significantly. This may be associated with the socioeconomic status of parents and their difficulty towards access to health services. Easy access to these medicines and lower socioeconomic status have been recorded to facilitate their use in the past, particularly in the lack of pediatric advice [27]. This study contrasts data from other countries reporting increased NPM administration in children among parents of higher socioeconomic and educational level, mostly attributed to convenience issues and their lack of time for visiting a physician $[1,2,28]$.

Prompt consultation from a pediatrician reduced the likelihood of using antipyretics, whereas advice by relatives had the opposite effect, indicating their strong influence on the family's health issues in our country. Information obtained through the Internet and television did not appear to have a significant influence on the administration of antipyretics-analgesics, unlike findings from an Italian study [29]. Finally, parents who disagreed that medicines should only be administered after a pediatric consultation were significantly more likely to use unprescribed antibiotics, while the probability of using both antipyretics and antibiotics increased significantly when information was sought by a pharmacist.

To our knowledge, this is the first study providing insight into the outpatient consumption of MWP, including both NPM and POM as well as information on factors potentially affecting their administration among a large cohort of preschool children. The low response rate $(43.1 \%)$ is a limitation of the study, as nonparticipating parents might present worse attitudes regarding MWP use. Another limitation of our study was that, since it was conducted in the Municipality of Athens among families of low and middle socioeconomic level, our findings cannot be generalized. Nevertheless, they may provide useful information on attitudes and associated factors that drive parents to use NPM. Finally, our results highlight the ongoing local malpractice of POM supply through pharmacies without the necessary prescription, stressing the need for continuous education, and stricter intervention policies in our country.

\section{Conclusion}

We found that an alarming proportion of parents in our country have administered medication without a prescription, including antibiotics, to their preschool children. Several sociodemographic factors, as well as the role of certain categories of health professionals, were identified as predictors for the above use, highlighting targets for intervention. The implementation of information campaigns at a national level, targeting parents and health professionals, regarding the prudent use of medication without a prescription in children and the serious consequences of their improper use as well as the strict control of disposing prescription-only medicines are considered essential.

\section{Conflicts of Interest}

The authors declare that they have no conflicts of interest.

\section{Acknowledgments}

The authors would like to express their gratitude to Dr. George Tsiftis, head pediatrician of the Municipal Nursery Schools of Athens, for his guidance and valuable assistance, and to all teaching staff and parents who participated in the study for their excellent cooperation.

\section{References}

[1] M. Trajanovska, E. Manias, N. Cranswick, and L. Johnston, "Use of over-the-counter medicines for young children in Australia," Journal of Paediatrics and Child Health, vol. 46, no. 1-2, pp. 5-9, 2010.

[2] M. Trajanovska, E. Manias, N. Cranswick, and L. Johnston, "Parental management of childhood complaints: over-thecounter medicine use and advice-seeking behaviours," Journal of Clinical Nursing, vol. 19, no. 13-14, pp. 2065-2075, 2010.

[3] Greek Government Gazette, "Terms and conditions for the release of pharmaceutical products for which their disposal is not subject to prescription" (Greek), No. 284/B, 2004, http://www .efex.gr/assets/files/862/file102.pdf.

[4] Greek Government Gazette, "Updated list of non -prescription drugs (NPMs)," No. 1222/B, 2014, http://www.eefam.gr/assets/ files/farmanomothesia/FEKb1222.14052014.pdf.

[5] P. Zed, K. Black, E. Fitzpatrick, S. Ackroyd-Stolarz, N. Murphy, and J. Curran, "Medication-Related Emergency Department Visits in Pediatrics: a Prospective Observational Study," Pediatrics, vol. 135, no. 3, pp. 435-443, 2015.

[6] M. D. Smith, H. A. Spiller, M. J. Casavant, T. Chounthirath, T. J. Brophy, and H. Xiang, "Out-of-hospital medication errors among young children in the United States, 2002-2012," Pediatrics, vol. 134, no. 5, pp. 867-876, 2014.

[7] M. Halim, H. Vincent, B. Saini et al., "Validating the Childrens Medicines Use Questionnaire (CMUQ) in Australia," Pharmacy World Science, vol. 32, no. 1, pp. 81-89, 2009.

[8] N. Birchley and S. Conroy, "Over-the-counter medicines in childhood: issues and concerns. A narrative review of the literature," Paediatric and Perinatal Drug Therapy, vol. 4, no. 4, pp. 161-167, 2001.

[9] S. Conroy, J. Collier, N. Birchley et al., "An examination of the risk management issues in the handling at home of overthe-counter medicines purchased for children," Pharmaceutical Journal, vol. 271, no. 7262, pp. 209-213, 2003.

[10] E. Skliros, P. Merkouris, A. Papazafiropoulou, A. Gikas, G. Matzouranis, C. Papafragos et al., "Self-medication with antibiotics in rural population in Greece: a cross-sectional multicenter study," BMC Family Practice, vol. 11, no. 1, 2010.

[11] Hellenic Centre for Disease Control and Prevention (HCDCP), E-Bulettin, vol. 60, 6th edition, 2016, http://www.keelpno.gr.

[12] T. Miron-Shatz, G. Barron, Y. Hanoch, M. Gummerum, and G. M. Doniger, "To give or not to give: Parental experience and adherence to the Food and Drug Administration warning about over-the-counter cough and cold medicine use," Judgment and Decision Making, vol. 5, no. 6, pp. 428-436, 2010. 
[13] U.S. Food and Drug Administration, "Briefing information. Joint meeting on the Non-prescription Drugs Advisory Committee and the Pediatric Advisory Committee," 2007, http:// www.fda.gov/ohrms/dockets/ac/07/briefing/2007-4323b1-00index.htm.

[14] U.S. Food and Drug Administration, "Use of Over-the-Counter (OTC) Cough and Cold Products in Infants and Children - Full Version," 2008, http://www.fda.gov/Drugs/DrugSafety/ DrugSafetyPodcasts/ucm077935.htm.

[15] World Health Organization, "Promoting Safety of Medicines for Children," 2007, http://www.who.int/medicines/publications/ essentialmedicines/Promotion_safe_med_childrens.pdf.

[16] M. D. Kogan, G. Pappas, M. Stella, and M. Kotelchuck, "Overthe-counter Medication Use Among US Preschool-age Children," JAMA: The Journal of the American Medical Association, vol. 272, no. 13, pp. 1025-1030, 1994.

[17] A. Walsh, H. Edwards, and J. Fraser, "Over-the-counter medication use for childhood fever: a cross-sectional study of Australian parents," Journal of Paediatrics and Child Health, vol. 43, no. 9, pp. 601-606, 2007.

[18] L. Vernacchio, J. Kelly, D. Kaufman, and A. Mitchell, "Medication Use Among Children < 12 Years of Age in the United States: Results From the Slone Survey," Pediatrics, vol. 124, no. 2, pp. 446-454, 2009.

[19] U.S. Food and Drug Administration, "Summary Minutes of the Joint Meeting of the Nonprescription Drugs Advisory Committee and the Pediatric Advisory Committee," 2011, http:// www.fda.gov/AdvisoryCommittees/CommitteesMeetingMaterials/Drugs/NonprescriptionDrugsAdvisoryCommittee/ucm246438.htm.

[20] W. M. Lee, "Drug-induced hepatotoxicity," The New England Journal of Medicine, vol. 349, no. 5, pp. 474-485, 2003.

[21] J. M. Garbutt, R. Sterkel, C. Banister, C. Walbert, and R. C. Strunk, "Physician and parent response to the fda advisory about use of over-the-counter cough and cold medications," Academic Pediatrics, vol. 10, no. 1, pp. 64-69, 2010.

[22] M. Mazer-Amirshahi, N. Reid, J. Van Den Anker, and T. Litovitz, "Effect of cough and cold medication restriction and label changes on pediatric ingestions reported to United States poison centers," Journal of Pediatrics, vol. 163, no. 5, pp. 13721376, 2013.

[23] S. G. Panagakou, M. N. Theodoridou, V. Papaevangelou et al., "Development and assessment of a questionnaire for a descriptive cross - Sectional study concerning parents' knowledge, attitudes and practices in antibiotic use in Greece," BMC Infectious Diseases, vol. 9, no. 1, article 52, 2009.

[24] European Centre for Disease Prevention and Control, "Surveillance of antimicrobial consumption in Europe 2012," 2014, http://ecdc.europa.eu/en/publications/publications/antimicrobial-consumption-europe-esac-net-2012.pdf.

[25] D. G. Contopoulos-Ioannidis, I. D. Koliofoti, I. C. Koutroumpa, I. A. Giannakakis, and J. P. A. Ioannidis, "Pathways for inappropriate dispensing of antibiotics for rhinosinusitis: a randomized trial," Clinical Infectious Diseases, vol. 33, no. 1, pp. 76-82, 2001.

[26] D. Plachouras, D. Kavatha, A. Antoniadou et al., "Dispensing of antibioticswithout prescription in Greece, 2008: another link in the antibiotic resistance chain," Euro Surveillance, vol. 15, 2010, http://www.eurosurveillance.org/ViewArticle.aspx?ArticleId= 19488.
[27] S. Tibdewal and M. Gupta, "Mother's use of medication in their children of preschool age," Indian Journal of Public Health, vol. 49, no. 1, pp. 27-29, 2005.

[28] C. R. Ecklund and M. Candice Ross, "Over-the-counter medication use in preschool children," Journal of Pediatric Health Care, vol. 15, no. 4, pp. 168-172, 2001.

[29] C. Pileggi, V. Mascaro, A. Bianco, and M. Pavia, "Over-thecounter drugs and complementary medications use among children in southern italy, BioMed Research International, vol. 2015, Article ID 413912, 8 pages, 2015. 


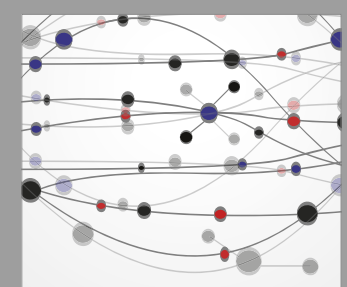

The Scientific World Journal
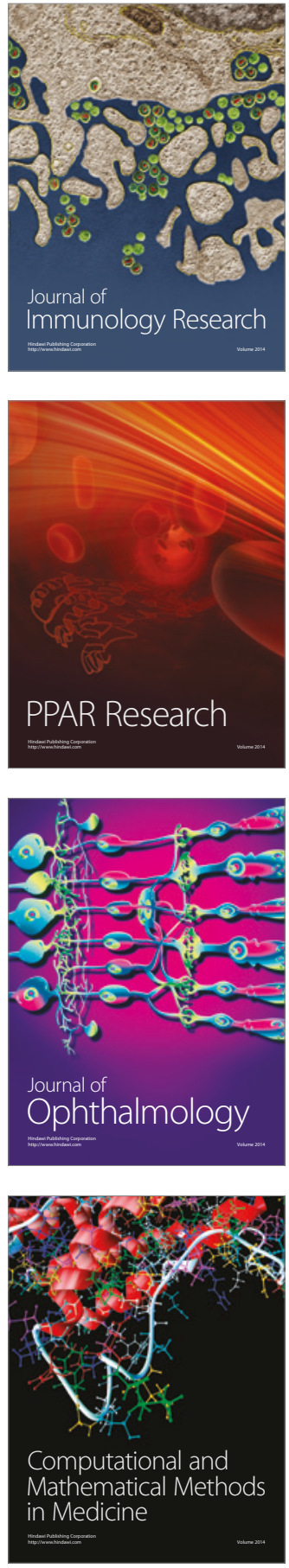

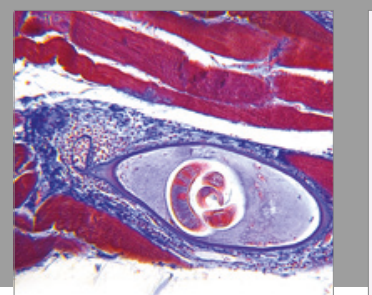

Gastroenterology Research and Practice
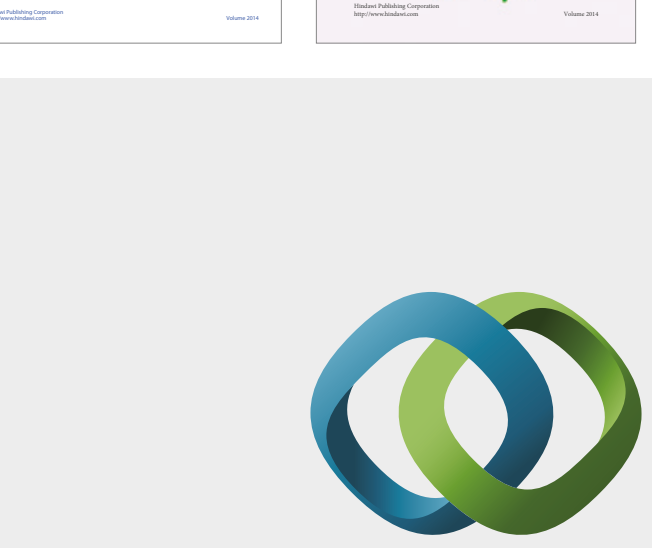

\section{Hindawi}

Submit your manuscripts at

https://www.hindawi.com
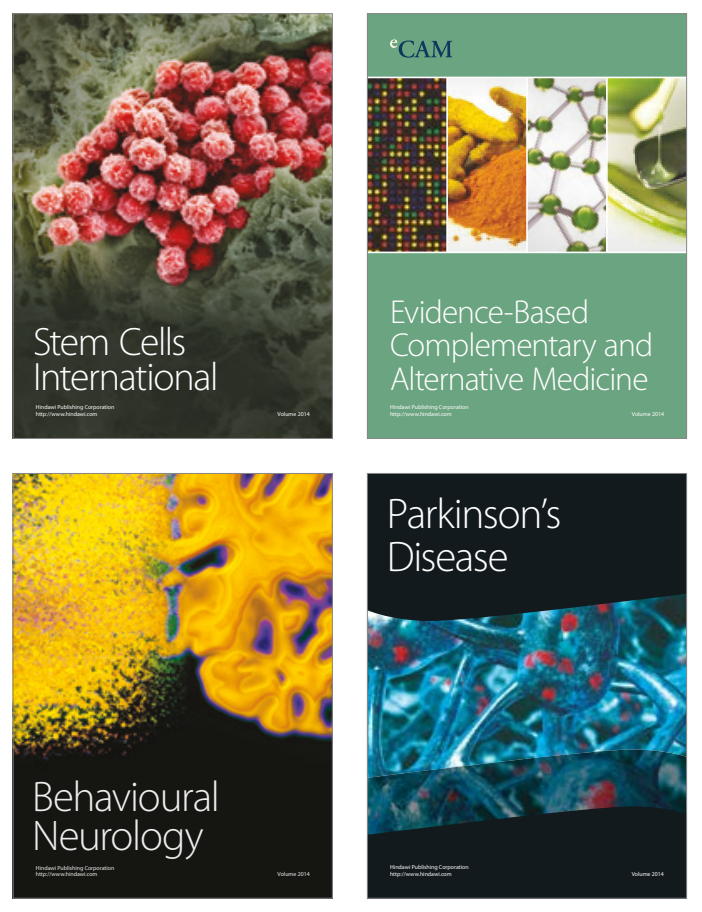
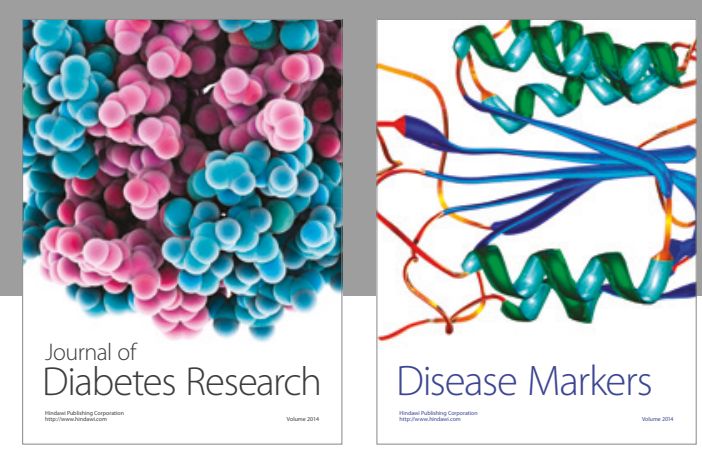

Disease Markers
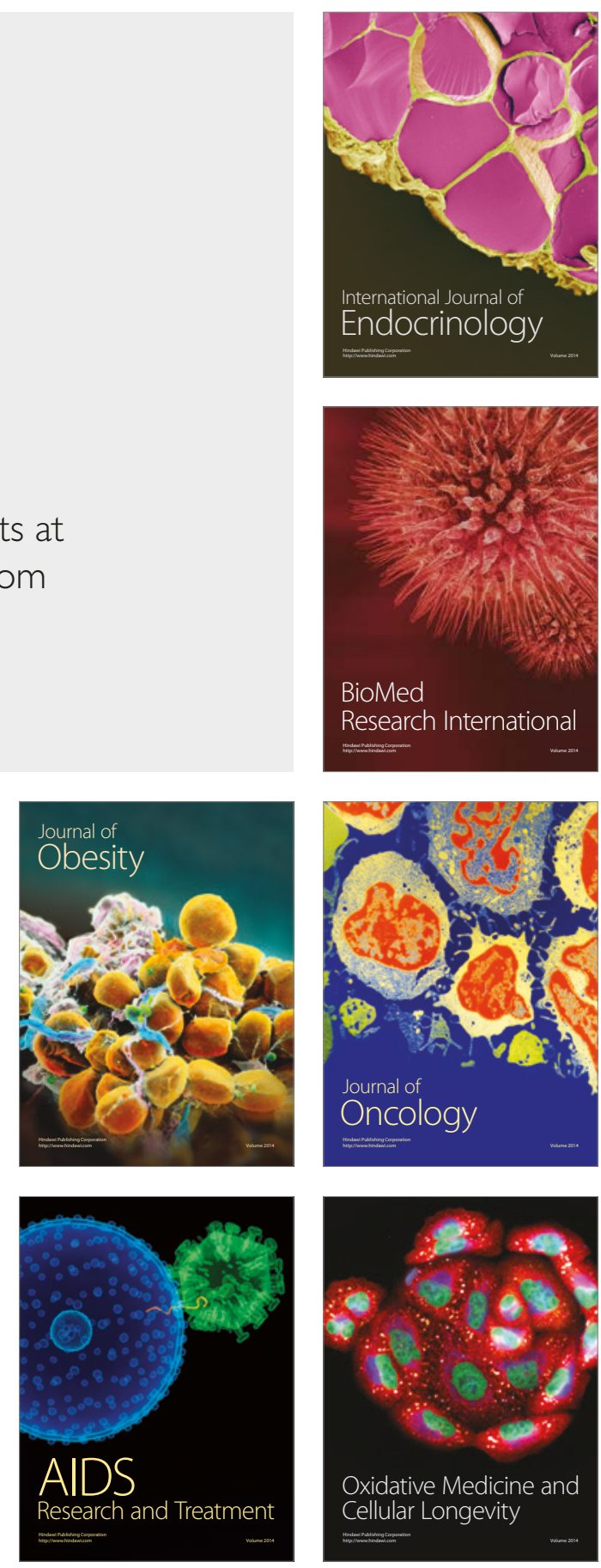